\title{
Integration Study of Cultural Context and Multimedia Technology
}

\author{
Caiyun, Zhang \\ School of Foreign Languages \\ Yan'an University \\ Yan'an, Shaanxi, 716000
}

\author{
Li, Zhang \\ School of Foreign Languages \\ Yan'an University \\ Yan'an, Shaanxi, 716000
}

\begin{abstract}
This paper aims to improve the learning ability of second language learners by integrating cultural context theory with multimedia technology. The author mainly uses questionnaires, network communication and field visits to explore the important significance of multimedia teaching to strengthening the intercultural awareness of second language learners. The survey results show that English teachers in the northwest of China have a low frequency of multimedia teaching, and students generally believe that cultural teaching is more important. Therefore, the author proposes four ways to integrate cultural context with multimedia teaching technology: situational way, guided way, heuristic way and participatory way. Although there may be many difficulties in the integration, the author expects that the integration model will bring teachers and students more practical results.
\end{abstract}

Keywords-Integration, Second Language Teaching, Cultural Context, Multimedia Technology

\section{CUltural CONTEXT}

The effective communication of culture depends more on the understanding of context, not just the expression of language.[1] The term "cultural context" is originally derived from Polish anthropologist Malinowski, who in his article of Classification Particle of Kiriwina Language suggests that semantic theory should indicate cultural contexts' influence to semantic situation. He believes that the meaning and function of one language component are constrained by certain social culture. He puts forward the context thinking, and divides the context into discourse context, situational context and cultural context. He believes that cultural context is the entire cultural background of language activities, such as social customs, traditions, history and so on. Both discourse context and situational context are the micro grasp of context, while cultural context is the macro grasp of context. Claire Kramsh believes that cultural context refers to all the knowledge accumulated by a society, namely "the common and longstanding ideological background knowledge of a nation in people's language communication, and the knowledge structure that people can understand through prediction and guessing in language communication. ". [2]

Therefore, second language learners should not only learn to use the target language from the perspective of grammar, but also do context-based discourse learning based on the understanding of target language's cultural background.
Therefore, the second language teaching and learning should not ignore the importance of cultural background knowledge

\section{QUESTIONNAIRE SURVEY}

\section{A. Object}

The survey respondents are mainly 1,110 teaching administrators, English teachers and English learners at school from 25 middle and high schools in five northwest provinces and cities, including 80 teaching administrators (56 males and 24 females), 280 English teachers (93 males and 187 females), and 750 students (323 males and 427 females).

\section{B. Purpose}

The survey is conducted mainly to study the northwest region:

(1) The use of multimedia in English teaching;

(2) The satisfaction of multimedia teaching in English teaching;

(3) The sensitivity of English learners to cultural awareness;

(4) English learners' demand for cultural awareness.

\section{Method}

The survey is conducted mainly by questionnaire, supplemented by network communication and field visits. In addition to questionnaire survey in 25 schools, the author also uses convenient network conditions to discuss topic-related problems with relevant teachers and students, such as enhancing intercultural awareness through multimedia courses. Meanwhile, different questionnaires are used for different surveyed groups. The survey of school administrators mainly focuses on multimedia facilities and their service condition and the satisfaction with the existing multimedia. Besides the above three aspects, the survey of English teachers also includes investigation of cultural awareness. Besides aspects mentioned above, the survey of English learners includes test and investigation of cultural awareness too.

\section{Validity}

A total of 1,110 questionnaires were distributed. Of which 80 were distributed to the teaching administrators of different schools, and 64 were recovered, with a recovery rate of $80 \%$. Among them, 60 questionnaires were valid, effective rate 
reaching $94 \%$. A total of 280 questionnaires were distributed to teachers of different schools, and 253 were recovered, with a recovery rate of $90 \%$. Among them, 247 questionnaires were valid, effective rate reaching $94 \%$. A total of 750 questionnaires were distributed to students of different schools, and 738 were recovered, with a recovery rate of $98 \%$. Among them, 694 questionnaires were valid, effective rate reaching $93 \%$.

\section{RESEARCH OF MULTIMEDIA TEACHING SITUATION IN NORTHWEST REGION OF CHINA}

Multimedia teaching refers to the application of multimedia technology in "Computer Assisted Instruction".[3] Multimedia teaching has been proposed as early as 1980s. After entering this century, with the rapid development of multimedia technology and network technology, the use of modern scientific and technological means to improve the level of education has become a major concern of various schools. Therefore the application of multimedia technology in teaching has become the mainstream of educational modernization development. However, the use of multimedia in English teaching in the northwest region mainly adopts the stand-alone mode, namely multimedia projection mode. In the classroom, teachers mainly operate the console and display the required knowledge through the projector and large screen. The following is the current state of multimedia teaching in northwest region obtained by questionnaire survey.

\section{A. The frequency of using multimedia to teach English}

According to the 1,001 valid questionnaires collected, it was found that $10.8 \%$ of the teachers frequently use multimedia, $34.21 \%$ use multimedia sometimes, $38.84 \%$ occasionally use multimedia, and $16.86 \%$ never use multimedia.

\section{B. Satisfaction with English multimedia teaching}

According to the questionnaire survey, $9.8 \%$ of the 1,001 investigated teachers are very satisfied with multimedia teaching, $26.1 \%$ were satisfied, $45.6 \%$ were not satisfied, and $18.5 \%$ were not satisfied with using the existing multimedia for teaching. Through interviews, we know that the reason why teachers are not satisfied with current multimedia teaching is mainly due to: (1) The existing multimedia hardware is very outdated and causes many problems in teaching, affecting the progress of the course. (2) Software that can be used for classroom teaching is rather single. Teacher can't combine teaching with students' learning situation, limiting teachers' classroom performance. (3) Teachers have received little multimedia technology training, resulting in that fewer teachers are willing to take the initiative to use multimedia for teaching.

\section{Quantitative reflection of cultural awareness test}

TABLE I. THE ACCURACY OF STUDENTS`ANSWERS TO THE QUESTIONS RELATED TO CULTURAL AWARENESS

\begin{tabular}{|c|c|c|c|c|c|c|c|c|c|c|c|c|c|c|c|}
\hline NO. & 1 & 2 & 3 & 4 & 5 & 6 & 7 & 8 & 9 & 10 & 11 & 12 & 13 & 14 & 15 \\
\hline Accuracy & $43 \%$ & $69 \%$ & $27 \%$ & $58 \%$ & $48 \%$ & $61 \%$ & $53 \%$ & $64 \%$ & $73 \%$ & $40 \%$ & $40 \%$ & $57 \%$ & $59 \%$ & $57 \%$ & $47 \%$ \\
\hline $\begin{array}{l}\text { Average } \\
\text { accuracy }\end{array}$ & & & & & & & & & $\%$ & & & & & & \\
\hline
\end{tabular}

The object of questionnaires is students. The above 15 questions in questionnaire are basic cultural questions. But the results show that the cultural awareness of learners can't reach the "passing" level.

\section{Quantitative reflection of cultural teaching's importance in English classroom:}

TABLE II. THE QUANTITATIVE RESULTS OF THE IMPORTANCE OF CULTURAL TEACHING

\begin{tabular}{|c|c|c|c|c|}
\hline Item & $\begin{array}{c}\text { Very } \\
\text { important }\end{array}$ & Important & $\begin{array}{c}\text { Not very } \\
\text { important }\end{array}$ & Not important \\
\hline $\begin{array}{c}\text { Number of } \\
\text { people }\end{array}$ & 42 & 55 & 2 & 1 \\
\hline Percentage & $42 \%$ & $55 \%$ & $2 \%$ & $1 \%$ \\
\hline
\end{tabular}

\section{The INTEGRATION OF CULTURAL CONTEXT WITH Multimedia TEACHING TECHNOLOGY}

\section{A. Situational way - integration with teaching model}

The situational teaching method is based on the intuitionistic teaching principle, and uses teaching materials such as images, sounds and objects to combine the language with image to produce intuitionistic and vivid effects, increasing students' perceptual knowledge. It can improve students' learning initiative and efficiency. The use of multimedia technology allows the situational teaching method to be better integrated into the new teacher-led and studentoriented teaching mode which strengthens the "learning" process. Due to the lack of consciousness in the current introduction of cultural factors into middle school English teaching, new teaching mode allows teachers easily and graphically teach students western culture through multimedia technology, so as to enable learners to have a greater interest in language learning.

\section{B. Guided way - integration with teaching methods}

Guided way adopts the steps of asking questions-analyzing problems-solving problems, taking teacher as the leading factor to lead students into the problem situation. It helps students carry out autonomous thinking and learn language in question, stimulating learners' initiative to learn. The guided way can be better combined with task-based teaching method. Teachers propose questions related to some cultural knowledge before class. Learners can think based on the contents of the text and put forward several hypotheses, or they can also use the network or library to look up information. Then teachers can use multimedia to further explain the specific cultural 
knowledge to students in class, getting rid of the cultural stumbling block in language learning for students.

\section{Heuristic way - integration with teaching content}

Heuristic teaching method refers to teaching activity which mobilizes, cultivates and exerts students' learning initiative and enthusiasm to stimulate thinking, explore knowledge and develop intelligence under the guidance of teachers.[4] Heuristic teaching method is mainly to inspire students' thinking and develop their ability to think and study independently. In heuristic teaching, teachers' guidance is relatively passive, and students pay more attention to practical opportunities. In view of the cultural part of the teaching content, teachers help students develop the habit of active thinking and exploration, and targeted guide students to stimulate their learning motivation.

\section{Participatory way - actual integration with teachers and teaching}

Participatory teaching emphasizes that learners truly participate in the process of classroom teaching, and attaches importance to learners' learning attitude, enthusiasm and initiative. The process of participatory teaching is not only about cognition, but also includes communication and interaction. Therefore, the teaching method pays more attention to interpersonal communication and cooperation, respect and love for the learners, and equality, democracy and harmony between teachers and students. Participatory teaching is learner-centered teaching. Its main purpose is to develop learners' creativity and multi-angle thinking ability. Therefore students can share the slides they download or make with teachers and students in class after learning more about the specific cultural knowledge through inquiry. It can improve students' initiative to study actively and their interests in language learning. Although the integration of the teaching method will use more classroom teaching time, it is of great benefit to students' long-term language learning habits.

\section{CHALLENGES IN INTEGRATION}

\section{A. Update of teachers' concept of education modernization and informationization}

With the continuous improvement of educational philosophy, basic English teachers' subject knowledge and skills have had great development. But teachers' enthusiasm is not high in the use of modern technology, and lacks enough educational technology concepts. Especially in the northwest of China where transportation and information are less developed, English teachers should comprehensively master the domestic and foreign advanced technology and new teaching methods, so as to form a strong information-based atmosphere for English teaching, laying the foundation for the cultivation of students who are suitable for the intercultural communication in international exchange.

\section{B. Improvement of teachers' Chinese and foreign cultural quality}

To improve the cultural quality of students, teachers must have a broader cultural knowledge. In recent years, due to the increasing emphasis on basic English education and the convenience of network resources, teachers' own language knowledge and cultural knowledge have had great improvement which allows them to make a more detailed description of the relevant European and American culture. However, when English teachers are bent on studying foreign cultural knowledge, they have forgotten our deep-rooted and profound 5,000-year-long Chinese culture. How can we have a deep understanding of foreign culture without understanding of Chinese culture? The essence of understanding other countries' culture is to know our own culture and make a comparison between them. Identification comes from comparison. Only in this way can the cultural knowledge learned be further internalized into our own knowledge. Therefore, English teachers should also improve their Chinese cultural knowledge while learning other countries' cultural knowledge.

\section{Enhancement of students' self-study consciousness}

Self-study is a kind of modern learning method which is proposed to distinguish from traditional reception learning. It treats students as the subject of learning, and achieves learning goal through students' independent analysis, practice, query and creation. Outline for Curriculum Reform of Basic Education (Trial) mentions in the specific goals of curriculum reform of basic education that: "Change the current situation that the implementation of curriculum pays too much attention to reception learning and rote learning, advocate students' active participation and exploration, cultivate students' ability to acquire and deal with new knowledge, analyze and solve problems, and communicate and cooperate." Today, with the rapid development of online media, students can freely imagine and search for the difficulties and doubts in their thinking in the convenient knowledge ocean. In English learning, emphasizing self-study under certain constraints will have unexpected gains.

\section{Enhancement of informationalized teaching consciousness of school administrators}

The deep reason that teachers lack the concept of education modernization and informationization is that school teaching administrators do not have strong informationalized teaching consciousness. Basic English teachers in northwest region are relatively fewer. Therefore teachers have to teach more time, making them not able to study the application of new technologies. At the same time, due to that teaching administrators don't have clear planning to promote school teachers to conduct informationization teaching, or have adequate measures to promote multimedia teaching, many schools only treat the software and hardware of multimedia teaching as its capital of advanced education. They haven't applied them to reality. Therefore, the school administrators must have strong informationalized teaching consciousness; carefully train the multimedia teaching technology of teachers. They need to determine the direction of multimedia teaching, and propose multimedia teaching-related documents, systems and measures, so as to further promote the education 
modernization and informationization in northwest region and put them into effect.

\section{CONCLUSION}

In short, the problems in English education in Northwest China have greatly influenced and restricted the application of multimedia technology in English education and the improvement of teaching effect in Northwest China. Only by taking effective measures to solve these problems as soon as possible can we promote the further application of multimedia technology in basic English education in Northwest China. The integration of cultural context and the use of multimedia can make language learners master the target language to the greatest extent with interest. This is also the ultimate goal of our language teaching.

\section{REFERENCES}

[1] Zhu Shuzhen. The context culture of intercultural communication [J]. Literature and Art, 2010, 02 (6): 106-106.

[2] Claire Kramsch. Language and Culture [M]. Shanghai: Shanghai Foreign Language Education Press, 2000. Page 23.

[3] Han Baolai. Multimedia Teaching-Computerized and Networked Teaching[M]. Jinan: Shandong Education Press, 2001. Page 1.

[4] Wang Tang. Heuristic Teaching Method [M]. Hubei: Hubei People's Publishing House, 1981. Page 4. 